\title{
SNOW AVALANCHES AND ACOUSTIC EMISSIONS
}

\author{
by
}

\section{R. A. Sommerfeld}

(U.S. Department of Agriculture Forest Service, Rocky Mountain Forest and Range Experiment Station, 240 West Prospect, Fort Collins, Colorado 80526, U.S.A.)

\author{
and H. Gubler
}

(Eidgenössisches Institut für Schnee- und Lawinenforschung, 7260 Weissfluhjoch/Davos,

\section{Switzerland)}

\section{ABSTRACT}

Analyses of several years of data show that acoustic emission activity is greater from unstable snowpacks than from stable snowpacks. Two types of signals have been identified: type I spikes and type II long-term elevation of the noise level. It is thought that the type I signals originate from macroscopic cracks. The type II signals may originate fron differential inovement on shearing surfaces, but this is less certain. Increased noise levels of both types correlate well with slope instability, when the slope stability is known. In some climates the limited range of signal detection might be a significant problem. A foam-mounted geophone set into the snow near active layers appears to be the best sensor available at present.

\section{INTRODUCTION}

Low-frequency acoustic emissions are observed from snowpacks before avalanche release (Gubler 1977[b], 1979, 1980, Sommerfeld 1977, 1980[a]); however, Bowles and St Lawrence (1977) reported negative results froin a single avalanche. The different results appear to be attributable to different techniques of data analysis and to ambiguities inherent in the observations (Sommerfeld 1932). Because of promising early results, we have continued to work on acoustic emissions from snow in the range 5 to $100 \mathrm{~Hz}$, with a view to increasing the reliability and accuracy of avalanche predictions. Direct relationships between acoustic emissions and slope stability, and clues to the release mechanisms of avalanches have been sought.

The work has shown that acoustic signals have predictive value. It also is evident that there are significant limits to the accuracy and reliability of the predictions. There is no precise method of determining the stability of a snow slope; only if it is possible to see the slope can one tell whether or not the slope has avalanched. This is a severe limitation because of poor visibility during storms. Not all low-stability slopes avalanche, as is evidenced by the fact that many more avalanches are released from artificially triggered slopes than from undisturbed slopes. Explosive control does not give complete evidence on stability. It is thought that explosives can force a marginally stable slope into instability (Williams 1978), or that explosives may not activate an instability under soine conditions if the placement is not correct (Gubler 1977[a] and [b]).
It is widely agreed that a snow slope can change its condition of stability radically, in either direction, in a few hours or days with no visible indication (Perla and Martinelli 1976). These circumstances add to the difficulty of determining the relationships between acoustic emissions and snow-slope stability. With ambiguities in the stability evaluation and the acoustic data, mistakes are possible on both counts in determining the relationship of levels of acoustic emission and slope stability. When they do not agree, it is possible that either may be in error. When they agree, it is possible that they are both in error. Under these circumstances, considerable judgment must be used in the evaluations. Also, it is necessary to record a large number of events to be sure that the data are real and do not represent random fluctuations. Since avalanches are rare events, it has taken several years to acquire a sufficient amount of data to support the conclusions given here. This paper is not meant to be the final word on the problem but to show, in our best judginent, where the field stands, which applications may be possible, and what further work is indicated. Acoustic sources in snow

Acoustic emissions in snow are displacement waves which can originate froin fractures in the snow or from the frictional sliding of gliding snow or snow creeping around obstacles (Leaird and Plehn in press). We propose the terms type I for the seismic type of signals originating from fractures, and type II for signals due to frictional sliding. As will be seen, the type I signals have been observed, but there is some ambiguity in the observations of type II signals. The breaking of bonds between ice grains seems to be the main source of acoustic emissions in seasonal snow (St Lawrence and Bradley 1973). The bonds between the chain grains that connect the more rigid clusters are more highly stressed (Gubler 1978[c]). These break, and part of the released energy propagates from the broken bonds as displacement wave packets. The frequency spectra of such events are in the ultrasonic range (St Lawrence and Bradley 1973) and are determined mainly by the speed of fracture propagation in the bond ice, the bond dianeter, and the resonance frequencies and dissipation of the intergranular network. At low strain-rates and small strains, ductile creep can occur in the ice network and redistribute the stress at a rate which is high enough to avoid macroscopic stress concentrations. Under these conditions, the bond breaks do not aggregate, but occur independently and generate no signifi- 
cant low-frequency acoustic components. This behavior is typical of ductile rupture and deformation.

If the local strain-rate is increased above about $10^{-4} \mathrm{~s}^{-1}$, ductile deformation may develop into brittle fracture propagation. In this case, the broken bonds aggregate into cracks with significant stress drops in the fracture planes, and lowfrequency components are generated. Their spectra are mainly deterinined by the ratio of the speed of fracture propagation in snow to the radius of the fractured area (Brune 1970, 1971, Dahlen 1974). As these cracks open, stress and strain-rate concentrations occur at the crack boundaries, localty driving the snow into more brittle behavior. This transition in behavior from stable and viscous to unstable and brittle, which is associated with the formation of cracks, is clearly shown in the work of Narita (1980). At strain-rates below $10^{-5} \mathrm{~s}^{-1}$, he observed stable, nonlinear, viscous behavior with the stress increasing with increasing strain-rate and no crack growth. Between $10^{-5}$ and $10^{-4} \mathrm{~s}^{-1}$, there was a transition zone where the strain-rate was relatively independent of stress with stable crack growth. At rates above $10^{-4} \mathrm{~s}^{-1}$, he observed unstable behavior where the stress decreased with increasing strain-rate and brittle fracture occurred. Singh (unpublished) observed similar behavior with larger samples and of lower density.

In a snowpack with portions under conditions of higher strain-rates, the strain-rate can be decreased and propagation of fractures arrested only by stress redistributions from fracturing planes to more stable parts of the snowpack. This leads to the conclusion that type I acoustic emissions indicate low stability in snowpacks. Ultrasonic emissions at low strainrates do not indicate instability (St Lawrence 1980), but may indicate strain softening as an initial process leading to strain-rate concentrations that cause propagating fractures and 1ow-frequency acoustic emissions.

When natural strain-rates are averaged over lengths of $3 \mathrm{~m}$, even under high, fracture-producing loading rates, they are in the range $10^{-7} \mathrm{~s}^{-1}$

(Sominerfeld 1979). Strain softening, acoustic emissions, and fracture cannot occur at these rates. The fact that Somnerfeld (1979) observed fractures leads to the conclusion that the strain must be concentrated in regions where the lengths are appreciably sinaller than $3 \mathrm{~m}$. Strain-rate concentrations at weak layers, and other inhomogeneities, may initiate ductile rupture and lead to stable or unstable fracture propagation. Locations in the snowpack where these processes start were termed primary fracture volumes by Gubler (1978[b] and [c]).

Fracture sizes (dislocation areas) may be estiinated from the frequency spectra of the low-frequency acoustic emissions (Brune 1970, 1971, Dahlen 1974). The signal frequencies in the range 10 to $100 \mathrm{~Hz}$ and a velocity of fracture propagation of about half the shear-wave velocity give dislocation radij of 0.1 to $1.0 \mathrm{~m}$. This is consistent with the results of Gubler (1977[a] and [b]), who found signal frequencies of about $30 \mathrm{~Hz}$ for dislocations of $1 \mathrm{~m}$ caused by small explosive loads. It also agrees with the conclusions of Sommerfeld $(1979,1980[a])$.

The origin of type II acoustic emissions is more problematic. They are characterized by an increase in the noise level which extends over a relatively long period of time. He believe that this type of emission results from frictional sliding, either by gliding snow or by differential movement around an obstacle or at a weak surface (Leaird and Plehn in press). However, an alternative hypothesis is that these signals are the cumulation of many low-level type I signals detected over a wide area. The determination of the character and source of this type of signal is difficult, since they generally have no distinct onset and have complicated frequency and phase characteristics.

\section{EXPERIMENTAL OBSERVATIONS} Instrumentation

The basic signals to be detected are lowfrequency displacement waves. The displacements are of the order of micrometers, and their direct measurement is impossible without a precise ground reference. The necessary instrumentation would be expensive and difficult to match to snow. The next most direct sensor is an inductive velocity gage with an inertial mass moving in a coil. The induced current is proportional to the velocity of the moving mass, which is suspended on a spring. To achieve good sensitivity, the mass must be relatively large, giving a low resonant frequency and good sensitivity to low frequencies. The resonance peak is usually suppressed with resistance damping.

The first observations of $10 w-f$ requency acoustic emissions from snow were made using velocity gages resonant at $28 \mathrm{~Hz}$ (Geospace HS-1 geophones*). These sensors were either mounted on concrete pads in the ground or were floated in the snowpack near avalanche starting zones (McNair and Wolfe 1977, St Lawrence and Bradley 1977, Sominerfeld 1977). The velocity gages used for observations reported in the present paper were made with critically damped geophones resonant at $5 \mathrm{~Hz}$ (Geospace HS-1) and, more recently, with critically damped geophones resonant at $8 \mathrm{~Hz}$ (Geospace GS-30). Although the sensitivity of the original snow-mounted geophones was found to be better, severe problems of resonance forced their abandoninent. Gubler (1977[a] and [b]) developed a sensor based on an acceleroneter with a mount of plastic foam. For good acoustic coupling the density of the sensor was matched approximately to the snow. These sensors were used for the present study in Switzerland.

For a given displacement amplitude, the output of an inductive device increases with signal frequency, while for a piezoelectric device such as an accelerometer, the output increases with the square of the frequency. Depending on the basic sensitivity of the sensors, there are sensitivity crossovers with respect to a given dislocation amplitude at different frequencies. For the GS-30 geophones and the type of accelerometers used in Switzerland, this crossover is just below $30 \mathrm{~Hz}$. The low-frequency geophones have the additional advantages of a low output impedance and significantly lower cost. Their main disadvantages compared to piezoelectric devices are a significant loss of sensitivity when they are tilted more than $15^{\circ}$ and their relatively large weight and size. Tilting is a serious problem in snow because creep can cause tilting of this magnitude in the course of a few months. Also, it is difficult to orient the sensors acccurately during installation under field conditions. The density-matched mounts embedded in the snow cover proved better in that they select for snow emissions in preference to environmental noise and avoid signal attenuation because of impedance mismatching between the snow and the ground. They can be embedded in the active emission layers, further increasing the signal-to-noise ratio.

To combine the advantages of both types of sensors, a lightweight geophone (Geospace GS-30) was mounted in a foam cylinder similar to that used for the accelerometer sensor. An X1000 preamplifier was also mounted in the cylinder as shown in Figure 1. The sensor system has a density of about $200 \mathrm{~kg} \mathrm{~m}^{-3}$, similar to older or windblown snow.

This sensor was tested for resonances on a shaker table. The response was smooth in the range 5 to $123 \mathrm{~Hz}$, which was the frequency range required in these studies. A peak at $150 \mathrm{~Hz}$ corresponded to the

* The use of trade and company names is for the benefit of the reader; such use does not constitute an official endorsement or approval of any service or product by the US Departiment of Agriculture to the exclusion of others that may be suitable. 


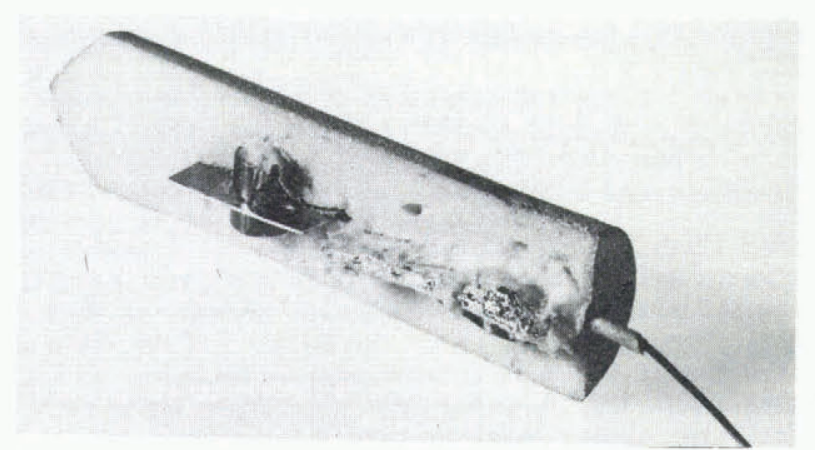

Fig.1. Cutaway view of a geophone and preamplifier mounted in a foam cylinder.

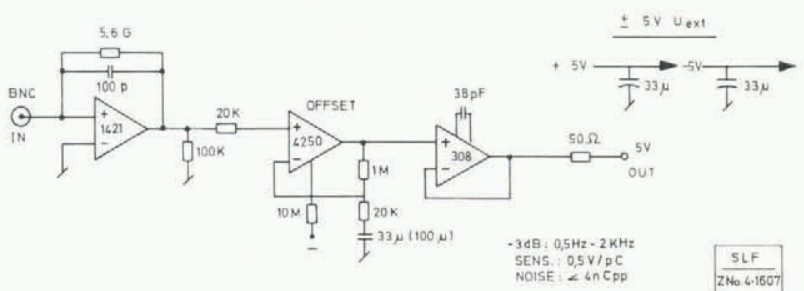

Fig.2. Circuit diagram of the charge amplifier for accelerometers.

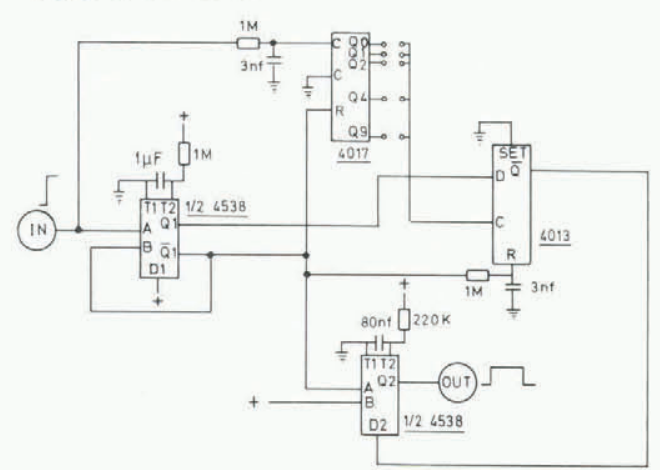

Fig.3. Circuit diagran of the preamplifier for geophones.

specification sheet supplied by the manufacturer, al though in the foam mount it was of somewhat lower ariplitude than specified. Field testing of this sensor has also shown a clean response and good sensitivity to snow noise, but occasional problems with excessive tilt.

Acoustic enissions from snow are of very low amplitudes. Displacement amplitudes are of the order of $10^{-7}$ to $10^{-6} \mathrm{~m}$ with velocities of $10^{-6}$ to $10^{-5} \mathrm{~m} \mathrm{~s}^{-1}$. The corresponding sensor outputs are 5 to $50 \mu \mathrm{V}$ for the GS-30 geophone and 1 to $10 \mathrm{nC}$ for the accelerometer sensor. A high level of amplification is necessary to bring the signals up to usable levels. Electronic noise pickup can be a severe problem, and care must be taken with shielding. Previous systems used in Colorado (McNair and Wolfe 1977, Sommerfeld $1980[a])$ have not been satisfactory in this regard, and the preamplifiers were found to have an annoying low-frequency resonance. The circuits shown in Figures 2 and 3 have proved very satisfactory in laboratory and field operation.

Data analysis and display

Methods of data analysis and display have varied anong workers. St Lawrence and Bradley (1977) displayed their data directly on a seismic drum recorder. This method tends to emphasize isolated spikes, which are the 10w-frequency components of type I signals, whereas the type II signals are of smaller amplitude and are inore persistent.

Sommerfeld $(1977,1980[a])$ recorded his signals on analog tape using direct-record circuitry and then analyzed them as (1) root mean square (RMS) ampli-

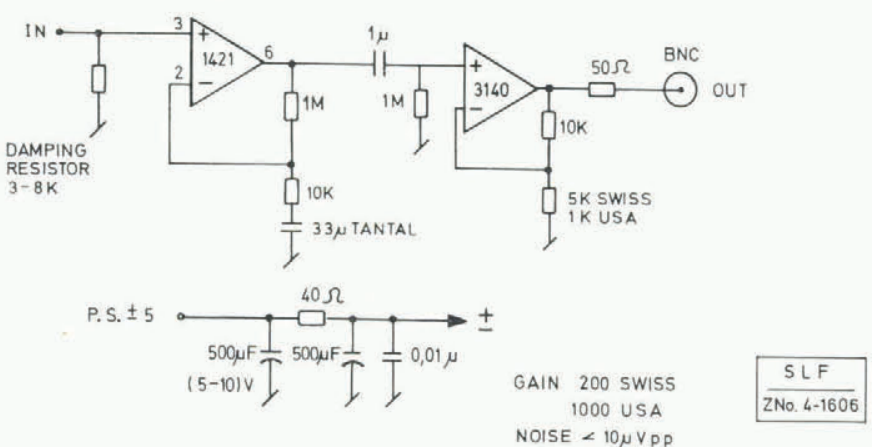

Fig.4. Circuit for pattern recognition.

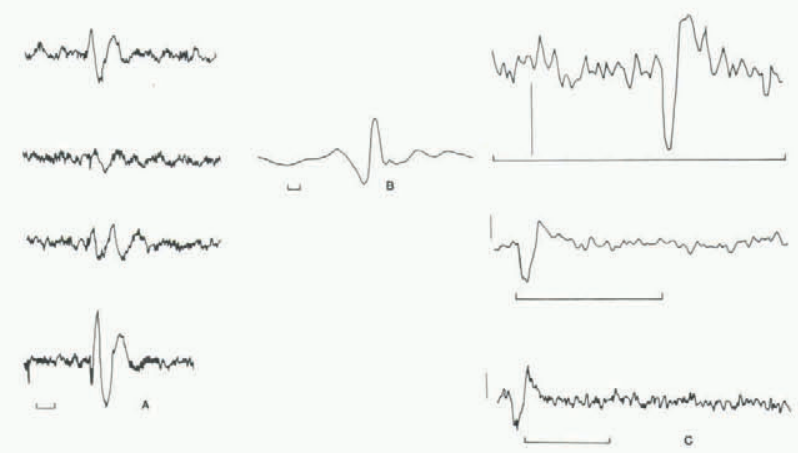

Fig.5. Type I spikes: A. Berthoud Pass, Colorado, B. Bridger Bowl, Montana, C. Weissfluhjoch/Davos, Switzerland. Horizontal bars represent 200 ms. Vertical bars in $\mathrm{C}$ represent $10^{-3} \mathrm{~m} \mathrm{~s}^{-2}$.

tudes, (2) counts above a constant level, and (3) with Fourier techniques. Tape recording preserves the original signal shapes and allows different analyses to be run on the same data. However, it is more subject to errors and to mechanical breakdowns because of the more complicated recording system. The directrecord method degrades the analysis of counts above a trigger level to some extent because the absolute voltage level is not very reliable over long periods of time with this technique.

Gubler's data, obtained between 1977 and 1982 , were collected directly as number of counts above a trigger level. This method loses some information concerning the signal shape. However, it has the advantages of reliability, mechanical simplicity, low power consumption for remote applications, and simple data handling and storage for online analyses. Analyses of RMS amplitudes and event counts have the disadvantage that they are sensitive to such environmental noises as airplanes, road traffic, wind, and natural and artificial seismic signals. However, the signatures of many of these signals are such that they may be differentiated from the type I signals by means of simple pattern recognition. Many of the signals due to environmental noise have large amplitudes or are long trains of waves. The circuit shown in Figure 4 is effective in reducing such signals. Only events that trigger the discriminator less than five times per second are counted. Additionally, direct ineasurements of ground signals with a groundmounted seismometer, and of airborne signals with a microphone, help with data interpretation.

\section{OBSERVATIONS AND DISCUSSION}

Two types of noise originating from the snow have been detected: isolated spikes (type I), and lowlevel, persistent noise (type II). Type I spikes have been observed at Berthoud Pass in Colorado, Davos in Sivitzerland, and Bridger Bowl in Montana (Fig.5). The differences in signal shape are mainly due to the different passbands of the sensing and recording systems. 


\section{Observations in Colorado}

In a study by Rose (unpublished), the locations of seven events were estimated from data obtained at Berthoud Pass. He also calculated stress drops and dislocation areas, al though here his assumptions may be open to criticism. This study shows that type I signals can be detected over the range of a few meters. A greater range may be possible by use of better sensors than were employed in this study. However, it is unlikely that a range of more than $10 \mathrm{~m}$ can be achieved for type I signals in daily operation.

The collection and analysis of data at Berthoud Pass have emphasized the presence of type II signals. This type of signal is incoherent but generally remains in a frequency band about $10 \mathrm{~Hz}$ wide for tens of hours. This frequency band usually appears in the range 20 to $40 \mathrm{~Hz}$, but it can be between 5 and $100 \mathrm{~Hz}$. The center frequency may slowly shift with time. For dry slab avalanches at Berthoud Pass, the RMS amplitude is very rarely more than three times the usual background noise originating from the environment. This is a very noisy site, and the background noise can vary by about $50 \%$, making it difficult to obtain an unambiguous estimate of the type II noise under all conditions.

Selecting for type I noises, embedding the sensors in the snow, and estimating the environmental noise by using external sensors might help to decrease these ambiguities.

The main evidence that the type II noise originates in the snow at Berthoud Pass is the fact that it correlates well with known slope stability in the immediate vicinity of the sensor. Of the total of 55 cases acquired at this location, there were 43 (78\%) correct "predictions" (the quotation marks are used since all data were analyzed after the events). There were 23 cases of low ambiguity. In these cases the enission levels were unambiguously high or low and the experimental slope was tested in some way. The correlation between the RMS signal level and slope instability was positive in 21 cases (91\%). The degradation in the information cones from 27 cases where there was significant ambiguity in the evaluations of slope stability. There were 17 (63\%) correct "predictions" in these cases where the estimate of the slope stability was made from tests on the surrounding avalanche paths. This agrees with the recent results of Judson (in press), who shows that there is very poor correlation among avalanche slopes in the Colorado Rocky Mountains. The remaining 5 cases were of ambiguous noise levels. Although they gave $100 \%$ correct "predictions", such ambiguous noise levels would be unusable for operational predictions. On the positive side, none of these were associated with major instabilities in the experimental area. The observed slides in the cases of ambiguous acoustic level were all shallow slides on a deep snowpack, and they all occurred at a slope distance of several meters from the sensors.

Solne discussion of the two erroneous cases is warranted. Although they were judged to show minimum ambiguity in both acoustic level and stability estimate, some doubt renains because of the difficulties involved in estimating stability. In the first case, the slope gave a high emission rate but was not released under foot testing, which is known to be a weak trigger. The possibility remains that it might have released under ski or explosives control. In the second case, the failure propagated into the experimental area from adjacent explosive control. However, some instruments in the new snow above the acoustic sensors were not disturbed. The cracks ceased to propagate a few meters before entering the sensor area, as is evidenced by the fact that the crown face had begun to thin. Thus, the snow immediately in the sensor area was stable. It is possible that the whole experimental slope was essentially stable, but susceptible to crack propagation from outside, in the manner of Perla's (1975) cooperative failure.

Two interesting sequences of high noise-noise decrease-avalanche should be discussed. This sequence is also observed in failures of rock in mines (Leighton and Steblay 1977, Hardy and Leighton 1980), but has not been adequately explained. It is possible that these are cases of crack arrest for a period of time in which a metastable equilibrium persists with low stability but no further crack growth, or that this is a manifestation of the Kaiser effect where a stress drop in the fracture area, followed by a stress buildup, does not produce further emissions until the stress level exceeds the previous level (Bradley and St Lawrence 1975). Observations in Switzerland

The main sources of decreased stability in the Colorado Rocky Mountains probably differ from those in the Alps. For midwinter conditions, wind loading of release zones without simultaneous precipitation is of much less importance in the Alps because the contributing areas and the catchment areas are smaller and the snow is usually of a lower erodibility. Loading occurs mainly during periods of heavy precipitation and may include wind transport during storms. In general, there is more precipitation in the Alps. Most natural avalanching occurs during or immediately after storms, with stability normally increasing much faster after the storms than is the case in the Colorado Front Range. The amount of precipitation is one of the riost important factors, while wind transport determines the range of aspects of avalanche occurrence. For spring conditions, including avalanching of gliding snow, solar radiation and temperature are the most important triggering factors.

Field experience and tests with numerical forecasting models (Obled and Good 1980, Buser personal comunication) show good correlations among avalanche occurrences for a given storm pattern or weather type. The "nearest day" model searches a library extending back for 20 years for similar situations with respect to weather type and snow-cover development. This model often shows similar patterns of avalanche occurrence for similar days.

Personnel involved in avalanche safety in the Alps have had good success in using test slopes to check stability for certain aspects and height ranges. Bonnet (1980) used seismic methods to show that a high correlation exists among avalanche occurrences in the French Alps. These circumstances indicate that it is much more accurate to estimate the stability of a slope in the Alps from surrounding slopes than it is in the Colorado Front Range. This leads to more reliable data.

Observations in Switzerland for the past five years show an almost perfect correlation between numbers of acoustic events measured in small stress zones and natural avalanching on similar but larger nearby slopes of the same aspect and elevation.

The Swiss site is environmentally quieter. Here, count rates that are up to 100 times larger than the variance of the background noise have often been recorded during unstable periods.

Tests with different threshold levels show that for index measurements in small stress zones the threshold should not be higher than $10^{-3} \mathrm{~m} \mathrm{~s}^{-2}$ for sensors based on accelerometers or $5 \times 10^{-6} \mathrm{~m} \mathrm{~s}^{-1}$ for velocity gages in the bandwidth 5 to $100 \mathrm{~Hz}$. In addition, the sensors should be placed in or very near the active layers. The sensors should be separated from the ground and the upper snow surface by 0.2 to $0.5 \mathrm{~m}$. This decreases sensitivity to ground noise and noise originating from wind and other surface disturbances.

Measurements made during three seasons from midDecember to the beginning of March yielded the following results. There were 42 days with an increased event rate on at least one sensor and with 
independent indications of low stability in the general area. There were 112 days with only background levels of events and no indications of natural avalanche occurrence or gliding. On 16 days, increased event rates were correlated with indications of gliding. Eight days with high event rates were recorded when there were no clear, independent indications of low stability. In seven cases, avalanches started in the immediate sensor area and were clearly predicted by the event rate. During spring 1981, there were many more days with high event rates caused by gliding and one avalanche starting from gliding snow. Days with known high environmental noise, such as that caused by maintenance, ski tourers, and aircraft, were excluded from the data. If dry, loose snow avalanches and shallow slab avalanches are excluded, no case has been observed where natural slab avalanches occurred at the location of the sensor or at corresponding slopes without increased event rates. In a few cases, avalanches were triggered by explosives one or two days after the event rate for the corresponding slope settled to its background level. These events are similar to the two cases from Colorado discussed above. This is an indication that the stability may renain at a low-level steady state with the strength and stress remaining constant without further fracturing or stress redistribution. Such a state would not be expected to produce the type of events which were monitored.

In some cases, ambiguities remain concerning the source of noise aithough the index indication was correct because wind noise, which was monitored, was not recorded. There were also cases where stability was decreased by solar radiation at low temperatures, with no glide. In one of these cases the slope was ski-tested at the location of the sensor. The slope was found to be stable in the morning and unstable in the early afternoon, in perfect agreement with the event count. In a second case, a nearby slope released naturally in about one hour during which the event rate was high. Further examples are given by Gubler (1977[b], 1979, 1980).

\section{COMPARISONS AND CONCLUSIONS}

The fact that type I noise is detected from widely different areas in Colorado, Montana and Switzerland indicates that the conclusions presented here are of wide application. Type I emissions suggest that there are inhomogeneities in the snow cover and that these cause local stress and strainrate concentrations, consistent with the observations of Sommerfeld (1979) and of Narita (1980). These conclusions also support the concept of primary fracture volumes suggested by Gubler (1978[a]. The frequency spectra of these emissions support the conclusion that these volumes are in the range $10^{-3}$ to $1 \mathrm{~m}^{3}$, agreeing with Sommerfeld (1980[b]), Singh (unpublished), and Narita (1980). These conclusions have important applications in the artificial release of avalanches (Gubler 1978[b]) and, in general, in the understanding of the mechanisms of avalanche release.

There is a clear difference in a comparison of the data on type II emissions from Colorado and Switzerland. The site in Colorado is a rough, rocky slope with a cold snowpack; gliding has never been significant on such slopes (Frutiger and Martinelli 1966). By comparison, the Swiss site is smoother and grass-covered, and the snowpack is usually warmer; gliding is more likely to occur under these conditions, and large glide cracks are occasionally observed here but never on the Colorado site. When the snowpack on the Colorado site becomes wet in the spring, it is known to be very stable and acoustic emissions always drop to a very low level. In contrast, on the Swiss site, full depth slabs starting from gliding snow correlate well with large-amplitude type II emissions. Often the opening and growth of glide cracks can be observed during periods of high, type II emission activity. Furtherraore, this type of activity correlates with weather conditions that would be expected to increase gliding (Gubler 1979).

Two hypotheses might explain the two types of emissions that have been observed. (1) They may have the same source. In this case the type I emissions would be those few that occur near the sensor, while the type II emissions would be the sum of many such spikes whose distorted signals are detected from a much wider area. (2) The sources of the two types may be different. It seems apparent that the type I spikes are due to limited tension cracking. The type II emissions may be due to relatively rapid shearing between layers; that is, a result of frictional sliding. The fact that the known glide between the snow and the ground gives the highest levels of type II noise lends support to the argument that this type of noise is due to frictional sliding. Furthermore, this second hypothesis is consistent with the results of seismic studies. Scholz (1968) presents evidence that both small rock samples and earthquakes give relatively inore low-amplitude signals than brittle fractures. Slow, stable frictional sliding of some sort between layers is thought to be a necessary precursor to snow avalanches (Perla and LaChapelle 1970, Smith and Curtis 1974, MCClung 1979). The resolution of this problem should lead to a better understanding of the mechanisms of avalanche release.

The information gained from studies of acoustic einissions from low-stability snowpacks shows that this is a promising technique for the prediction of wet slab avalanches. It might also be used as an additional source of information in the prediction of large, dry slab avalanches at specific locations. The prediction of small, dry slab avalanches is very difficult and probably not possible under realistic operational conditions. A limitation concerns the restricted range of detection of the signals. In Colorado, Judson (in press) has found very poor correlation among the stabilities of different avalanche paths. This is consistent with the results from Berthoud Pass, as discussed above. It is unknown whether Judson's results are specific to the Colorado Front Range or are more general. Experience in the Alps suggests that Judson's results may only be valid for clinates with conditions of low precipitation and high winds.

The best combination of data analysis and display is still problematic. The interpretations of data presented here were made by very experienced observers. The fact that interpretation requires a high degree of judgment indicates that the possibility of error is correspondingly high. An effort was made in the present analysis to avoid prior knowledge affecting the noise evaluation, but a procedure of this type is notoriously risky. Better techniques for data analysis and display are necessary if acoustics are to be used in routine prediction of avalanches so that the amount of judgment necessary is reduced.

If a combination of type I and type II emissions is to be monitored, a display of RMS amplitudes with some time-averaging, including a system to reduce environinental noise, would be necessary. This type of monitoring is indicated where creeping or gliding snow is of primary importance. For type I emissions, the event-counting inethod gives better discrimination between high and low emission periods. Count rates inay be two orders of magnitude higher while an RMS system might produce a maximum of a factor of three differences, as discussed above.

In either case, a density-matched sensor in the snow must be used for dry slab prediction. Also, some type of sensor for monitoring environmental noise, both from the air and the ground, would increase the reliability of the predictions.

A technique that has not yet been tried is that suggested by Scholz (1968). A change of slope of the $\log$ of the number of events as a function of amplitude indicates a change in the failure mechanism in 
rocks. If the two types of noise are from different sources and if the noises are produced from relatively discrete sources, such a technique should prove useful in increasing the reliability of predictions. Leighton (personal communication) has found that even a crude measure of event number versus amplitude is useful in decreasing the ambiguities in predictions of failure of mine walls.

\section{REFERENCES}

Bonnet G 1980 Détection d'avalanches par méthode sismique. Neige et Avalanches. Revue de l'Association Nationale pour l'Etude de la Neige et des Avalanches 24: 30-41

Bowles D, St Lawrence W F 1977 Acoustic emissions in the investigation of avalanches. Proceedings of the Westerm Snow Conference, 45th annual meeting: 88-94

Bradley C C, St Lawrence W F 1975 Kaiser effect in snow. Intermational Association of Hydrological Sciences Publication 114 (Symposium of Grindelwald 1974 - Snow Mechanics): 145-154

Brune J N 1970 Tectonic stress and the spectra of seismic shear waves from earthquakes. Journal of Geophysical Research 75(26): 4997-5009

Brune J N 1971 Correction [to Brune 1970]. Joumal of Geophysical Research 76(20): 5002

Dahlen F A 1974 On the ratio of P-wave to S-wave frequencies for shallow earthquake sources. Bulletin of the Seismological Society of America 64(4): $1159-1180$

Frutiger H, Martinelli M Jr 1966 A manual for planning structural control of avalanches. US Department of Agriculture. Forest Service. Research Paper RM-19

Gubler H 1977[a] Artificial release of avalanches by explosives. Journal of Glaciology 19(81): 419-429

Gubler H 1977[b] Künstliche Auslösung von Lawinen durch Sprengungen. Mitteilungen des Eidgenössischen Institutes für Schnee- und Lowinenforschung 35

Gubler H 1978[a] An alternate statistical interpretation of the strength of snow. Journal of Glaciology 20(83): 343-357

Gubler H 1978[b] Determination of the mean number of bonds per snow grain and of the dependence of the tensile strength of snow on stereological parameters. Joumal of Glaciology 20(83): 329-341

Gubler H 1978[c] Künstliche Auslösung von Lawinen durch Sprengungen. Eine Anleitung für den Praktiker. Mitteilungen des Eidgenössischen Institutes für Schnee- und Lowinenforschung 36

Gubler H 1979 Acoustic emission as an indication of stability decrease in fracture zones of avalanches. Journal of Glaciology 22(86): 186-188

Gubler H 1980 Simultaneous measurements of stability indices and characteristic parameters describing the snow cover and the weather in fracture zones of avalanches. Joumal of Glaciology 26(94): 65-74

Hardy H R Jr, Leighton. F W (eds) 1980 Proceedings of the second Conference on Acoustic Emissions/ Microseismic Activity in Geologic st muctures and Materials... Pennsylvania... 1978. ClausthalZellerfeld, BRD, Trans Tech Publications

Judson $A$ In press. On the potential use of index paths for avalanche assessment. Joumal of Glaciology

Leaird $\mathrm{J} D$, Plehn $J$ In press. Acoustic emission monitoring on avalanche prone slopes. In Hardy H R Jr, Leighton F W (eds) Proceedings of the third Conference on Acoustic Emissions/ Microseismic Activity in Geologic Structures and Materials... Pennsylvania... 1981

Leighton F W, Steblay B J 1977 Applications of microseismics in coal mines. In Hardy $H \mathrm{R} \mathrm{Jr}$, Leighton $\mathrm{F}$ W (eds) Proceedings of the first Conference on Acoustic Emissions/Microseismic
Activity in Geologic structures and Materials. Clausthal-Zellerfeld, BRD, Trans Tech Publications: 205-229

McClung D M 1979 Shear fracture precipitated by strain softening as a mechanism of dry slab avalanche release. Joumal of Geophysical Research 84(B7): $3519-3526$

McNair D, Wolfe F Jr 1977 An acoustic emissions inonitoring system for avalanche snowpacks. US Department of Agriculture. Forest Service. Research Note RM-340

Narita H 1980 Mechanical behaviour and structure of snow under uniaxial tensile stress. Journal of Glaciology 26(94): 275-282

Obled C, Good W 1980 Recent developments of avalanche forecasting by discriminant analysis techniques: a methodological review and some applications to the Parsenn area (Davos, Switzerland). Joumal of Glaciology 25(92): 315-346

Perla R I 1975 Stress and fracture of snow slabs. Intermational Association of Hydrological Sciences Publication 114 (Symposium of Grindelwald 1974 Snow Mechanics): 208-221

Perla R I, LaChapelle E R 1970 A theory of snow slab failure. Jourmal of Geophysical Research 75(36): 7619-7627

Perla R I, Martinelli M Jr 1976 Aval anche handbook. US Department of Agriculture. Forest Service. Agriculture Handbook 489

Rosé C C Unpublished. Seismic moment, stress drop, strain energy, dislocation radius and location of seismic acoustical emissions associated with a high alpine snowpack at Berthoud Pass, Colorado. (PhD thesis, Montana State University, 1981)

St Lawrence WF 1980 The acoustic emission response of snow. Joumal of Glaciology 26(94): 209-216

St Lawrence W F, Bradley C C 1973 U1trasonic emissions in snow. US Department of Agriculture. Forest Service. General Technical Report RM-3

St Lawrence W F, Bradley C C 1977 Spontaneous fracture initiation in mountain snow-packs. Joumal of Glaciology 19(81): 411-417

Scholz C H 1968 The frequency-magnitude relation of microfracturing in rock and its relation to earthquakes. Bulletin of the Seismological Society of America 58(1): 399-415

Singh $H$ Unpublished. A finite element model for the prediction of dry-slab avalanches. (PhD thesis, Colorado State University, 1980)

Sinith F W, Curtis J 01974 Stress analysis and failure prediction in avalanche snowpacks. International Association of Hydrological Sciences Publication 114 (Symposium of Grindelwald - Snow Mechanics): $332-340$

Sommerfeld R A 1977 Preliminary observations of acoustic emissions preceding avalanches. Joumal of Glaciology 19(81): 399-409

Sommerfeld R A 1979 Accelerating strain preceding an avalanche. Joumal of Glaciology 22(87): 402-404

Sommerfeld R A 1980[a] Acoustic emissions from unstable snow slopes. In Hardy $\mathrm{H} \mathrm{R} \mathrm{Jr}$, Leighton $F W$ (eds) Proceedings of the second Conference on Acoustic Emissions/Microseismic Activity in Geologic Structures and Materials...Pennsylvania... 1978. Clausthal-Zellerfeld, BRD, Trans Tech Publications: $319-330$

Sommerfeld R A 1980[b] Statistical models of snow strength. Joumal of Glaciology 26(94): 217-223

Sommerfeld R A 1982 A review of snow acoustics. Reviews of Geophysics and Space Physics 20(1): 62-66

Williams K 1978 Post-control avalanche releases. In Deuxième Rencontre Intermationale sur la Neige et les Avalanches, 12-13 et 14 Avril 1978, Grenoble, France. Comptes Rendus. Grenoble, Association Nationale pour l'Etude de la Neige et des Avalanches: $251-263$ 